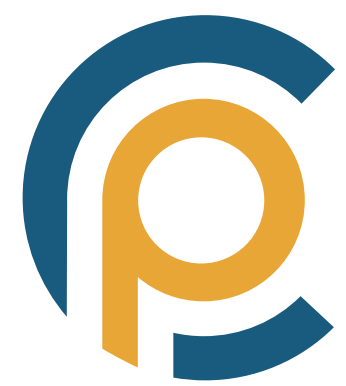

\title{
La Lucha Cinematográfica entre Oriente y \\ Occidente. \\ Studio Ghibli versus Disney
}

The Cinema's Fight between Eastern and Western. Studio Ghibli versus Disney

Recibido: 17/04/2020 | Revisado: 26/04/2020 | Aceptado: 02/06/2020 | Publicado: 30/06/2020

\section{Vicente Monleón Oliva}

Universidad de Valencia

vicente.monleon.94@gmail.com

https://orcid.org/0000-0001-8357-1316

Resumen: El cine de animación es uno de los elementos, de la cultura visual, con un impacto en la confección de la identidad y personalidad de quienes pertenecen a la infancia. Por un lado, se cuenta con Disney en el territorio occidental y, por otro lado, con Studio Ghibli en el sector oriental, como estudios cinematográficos de animación punteros en la industria. Ambas se centran en los mismos temas, pero difieren en la manera de abordarlos. Además, se seleccionan para esta investigación por el gran alcance mediático que ambas suponen. Por ello, se considera sumamente necesario analizar, crítica y cualitativamente, ambas compañías cinematográficas para manifestar los mensajes que calan en el subconsciente de quienes consumen los filmes tras un visionado pasivo de estos. Esta investigación se centra en el cine entendido como arte, concretamente en el de animación occidental (Disney) y oriental (Studio Ghibli). De esta manera, las conclusiones más destacadas se posicionan en la diferencia en cuanto al tratamiento del feminismo y amor romántico. Mientras que en la productora occidental perduran estereotipos y roles de género anclados en el patriarcado, la compañía oriental defiende un cambio de paradigma desde posicionamientos menos excluyentes. Asimismo, también hay una diferencia en el tratamiento del medio ambiente. Disney arremete contra este mientras que Studio Ghibli se esfuerza en preservarlo.

Palabras clave: cultura visual, animación, audiovisual, feminismo, amor romántico, religión, medio ambiente, educación Infantil.

\begin{abstract}
The animated cinema is one of the elements of visual culture, with an impact on the preparation of the identity and personality of those who belong to childhood. On the one hand, it has Disney in the western territory and, on the other hand, with Studio Ghibli in the eastern sector, as leading animation film studios in the industry. Both focus on the same themes, but differ in how they are addressed. In addition, they are selected for this research due to the great media coverage that both entail. For this reason, it is considered extremely necessary to analyze, critically and qualitatively, both film companies to express the messages that permeate the subconscious of those who consume the films after their passive viewing. This research focuses on cinema understood as art, specifically that of Western (Disney) and Eastern (Studio Ghibli) animation. In this way, the most outstanding conclusions are positioned in the difference regarding the treatment of feminism and romantic love. While stereotypes and gender roles anchored in patriarchy persist in the western production company, the eastern company defends a paradigm shift from less exclusive positions. Likewise, there is also a difference in the treatment of the environment. Disney lashes out at it while Studio Ghibli strives to preserve it.
\end{abstract}

Keywords: visual culture, animation, audiovisual, feminism, romantic love, religion, natural environment, early childhood education. 
La cultura visual se entiende como un conjunto de información que se percibe a través de los órganos de la visión y que contribuye a crear un imaginario, mentalidad, ideología, pensamiento y uniformidad en la comunidad. De hecho, de acuerdo con Acaso (2006) esta se manifiesta con gran presencia en la cotidianidad a través de múltiples recursos como la publicidad, la televisión o el cine. ¿Cuál es su finalidad? El bando del poder pretende crear, reproducir, perpetuar, asentar y/o afirmar unas conductas acordes con su posicionamiento político; valiéndose del desconocimiento de quienes consumen el producto y de la ausencia de una alfabetización visual que contribuye al desarrollo del pensamiento crítico en la ciudadanía.

Consecuentemente, se debe contemplar el impacto en el colectivo infantil en lo que respecta al desarrollo de su personalidad e identidad como personas (Monleón, 2018). Dependiendo de los mensajes audiovisuales percibidos y asimilados a lo largo de la infancia, se forja un miembro concreto en la sociedad donde se encuentra. Estos mensajes también influyen a las personas adultas, pero en una medida menor. Por ello, la gran necesidad social se focaliza en analizar críticamente los largometrajes de animación para animar a quienes forman parte de las plantillas docentes a utilizarlos de manera lógica y en aras de conseguir unos fines educativos y pedagógicos. No simplemente como un recurso que agrada a quienes son discentes y que les facilita la tarea de "adormecerles" e impedirles un desarrollo desde posicionamientos críticos, sospechosos y activos.

Pero, ¿qué se entiende por alfabetización visual? De acuerdo con Farías y Seguel (2014) esta consiste en un proceso de enseñanza-aprendizaje que facilita a quienes son menores métodos para decodificar, analizar y criticar los mensajes que les son transmitidos a través de la cultura visual. El objetivo principal de ésta consiste en romper las barreras que supone la pasividad con la que se tiende a consumir los largometrajes de animación en las aulas de Educación Infantil, los cuales generan una comunidad uniformada que, como norma general, atenta contra la diversidad y contra los valores de tolerancia y respeto. Con todo, esta investigación se centra en el cine entendido como arte, concretamente en el de animación occidental (Disney) y oriental (Studio Ghibli).

\section{El monopolio de Disney en el territorio occidental y su contra-discurso oriental: Studio Ghibli}

En el continente norteamericano destaca la presencia de Disney como productora de animación infantil con preponderancia en la sociedad. De hecho, tal y como comparte Mollet (2013) sabe cómo ganarse una cartilla de clientes que sobrepasa el componente generacional y contextual a lo largo de un siglo de historia. Su seña de identidad son las historias clásicas revestidas de una dulzura empalagosa junto a un componente de cuento de hadas con final feliz (Lluch, 2006). Además, el acompañamiento musical y el tratamiento en el diseño de animados contribuyen al agrado que generan estos audiovisuales en quienes reciben esta información visual. Por ello, se precisa conocer cuáles son los mensajes, actitudes, conductas, etc., que perpetúa; siendo primordial difundir un conocimiento de estos entre la población.

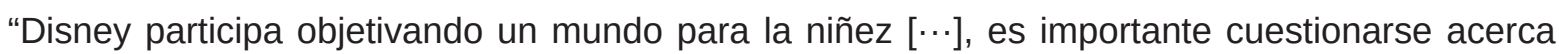
de las consecuencias que pudiera acarrear en un momento dado la representación que se hace de la mujer en los productos mediáticos que difunde esta empresa" (Maeda, 2011, p. 97). Giroux (1995), como autor clásico en la literatura especializada de análisis Disney, argumenta que esta industria de animación occidental entretiene, transmite y asienta en el subconsciente de las personas consumidoras unos mensajes sobre los comportamientos sociales de occidente. "A cada objeto representado, significante, corresponde un significado, fácil de identificar por la sociedad. Son símbolos que nos acompañan durante años, aunque susceptibles a cambios interpretativos" (del Arco, 2007, p. 2). Según Lluch (2006) llega la imagen de una sociedad regida por la estructura patriarcal dentro del núcleo familiar, donde el hombre se erige como dominante y macho alfa, mientras que la mujer es sumisa y queda relegada al ámbito del hogar. 
Con estas películas, Disney ha gestado la imagen de un nuevo niño, el niño de la globalización. El deseo de una sociedad que lo consume y le exige ser pero sin orientarlo, que le pide un desapego a la familia para buscar su unidad en lugares fuera de casa. Los de arriba ejercen la coerción, castigos, amenaza, represión, dominio, chantaje, instando al hijo-niño a que crezca cada vez más rápido, que incluso sea autosuficiente y productivo a corta edad, que se valga por sí mismo, que se haga cargo de los deseos frustrados de sus padres. (Asebey, 2011, p. 245)

Por tanto, Disney se define como una productora de animación que no pretende simplemente distinguir el estilo particular de los Estados Unidos, sino reforzar los valores y las prácticas culturales de la América post-colonizada; perdurándolos a lo largo de un siglo de existencia. Además, se le conoce como una "fábrica de sueños" ya que tiene un gran potencial para adormecer a la comunidad consumidora del producto sin ser capaz de generar en esta una reflexión crítica sobre los mensajes transmitidos a través de los largometrajes.

En contraposición a Disney se muestra como una competencia oriental la productora Studio Ghibli. Esta es una compañía fantasiosa y seguidora del estilo anime (Papalini, 2006). Al igual que su contrincante, también ejerce una gran influencia en quienes consumen sus productos (Martínez, 2015). De hecho, los temas tratados en ambas son iguales en cuanto a forma, pero difieren severamente en el contenido; es decir, la manera de abordar los mensajes, las ideologías, etc., son enfocados desde otros posicionamientos sociales (Gómez, 2016).

El anime o cine de animación japonés se concibe como una alternativa para quienes viven en una zona occidental, a través de historias que provienen de la cultura oriental, siendo aptas para todo tipo de público (Napier, 2001).

El marco fantasioso del grupo de las producciones japonesas importadas, los personajes se vuelven verosímiles: son contradictorios, se equivocan, tienen malos sentimientos y sienten impulsos eróticos, pareciéndose notablemente a sus públicos y sus vivencias. Al contrario de lo que sucede con la historieta norteamericana clásica, los manga siempre han tenido contacto con la vida cotidiana, lo que facilita la identificación con los personajes centrales. No se trata de gente increíble haciendo cosas extraordinarias, sino de gente común haciendo cosas normales en un marco imaginativo y lleno de misteriosas referencias a desvelar, con toda la complejidad de las acciones en donde los malos no lo son tanto ni los buenos son perfectos; el bien no siempre triunfa y los finales pueden no ser felices.(Papalini, 2006, pp. 43-44)

Esta compañía se funda con Hayao Miyazaki en 1985, momento a partir del que se convierte en una gran potencia mundial (Martínez, 2015). Dicha influencia se explica por la atribución de humanismo a quienes las protagonizan y a las historias que se transmiten (Robles, 2013). De hecho, las producciones de Studio Ghibli se muestran como una alternativa para la educación del colectivo infantil desde una perspectiva diferenciada de la clasista, separatista y exclusiva que defiende Disney (Aguado y Martínez, 2016).

\section{Métodos}

En esta investigación de corte artístico hay una necesidad en conocer la ideología de la productora de animación Disney y compararla con su competencia opuesta Studio Ghibli. Por ello, el objetivo principal es analizar, por medio de una comparativa, las compañías de animación con una gran influencia en la confección de identidades y personalidades en el colectivo infantil que consume estos productos, resultando como objeto de análisis las empresas cinematográficas Disney y Studio Ghibli. Todo ello, para establecer una serie de directrices pedagógicas a tener en cuenta cuando estos recursos sean utilizados en las aulas de Educación Infantil, para favorecer un desarrollo integral y alfabetización audiovisual de quienes pertenecen a la infancia. Aunque, para conseguir el cumplimiento de dicho fin se necesita una segmentación en objetivos específicos. Estos se centran en las variables de estudio a analizar en ambas colecciones. 
, Estudiar los roles de género y estereotipos sexuales que se transmiten entre ambas productoras.

, Conocer el enfoque sentimentalista que se adopta en cada una de estas compañías.

, Manifestar los fanatismos religiosos que acontecen en los largometrajes creados por cada empresa.

, Valorar la cabida que tiene la preservación del medio ambiente.

Debido a la gran abundancia de largometrajes que hay en la productora de Walt Disney, se considera oportuno acotar el marco de análisis, reduciendo el objeto de estudio a los 60 largometrajes que componen la colección "Los clásicos" (1937-2016). Mientras que, en el caso de Studio Ghibli, se seleccionan todos los filmes que crea la compañía, ya que en conjunto son un total de 22. De toda la muestra, se referencian a lo largo de la exposición de resultados aquellos ejemplos que se relacionan directamente con la temática presentada; valiéndose como ejemplos puntuales de entre una pluralidad.

Asimismo, se sigue una metodología cualitativa (Ramos, 2015) para el análisis de los largometrajes en torno a los 4 temas planteados: los estereotipos sexuales y roles de género diferenciados, el enfoque sentimentalista, los fanatismos religiosos, también la preservación del medio ambiente. Concretamente, se estudian las imágenes para establecer diferencias/semejanzas entre ambos productos artísticos. De esta manera, se recurre a la Investigación Basada en Imágenes (IBI) a la que hace referencia Alonso-Sanz (2013) en su publicación y que justifica el corte y la relación artística que presenta este trabajo. Todo este análisis metodológico se desarrolla partiendo de la incidencia que los filmes de Disney y Studio Ghibli tienen para los niños y niñas de Educación Infantil (0-6 años).

A continuación, se comparte el método seguido en el desarrollo de todo el análisis. En primer lugar, se efectúa un visionado de los 60 (Anónimo, 2020) y 22 (Anónimo, 2016) largometrajes correspondientes a cada colección, Disney y Studio Ghibli respectivamente. Se atiende a una revisión crítica en base a los 4 temas establecidos. Para, finalmente, analizar cuáles son las diferencias y similitudes entre ambas compañías.

\section{Exposición y discusión de resultados}

Por un lado, en cuanto a los roles de género y estereotipos sexuales se manifiesta una preservación de esta estructura del patriarcado en la colección "Los clásicos" Disney, ya que en 56/60 películas que la componen se manifiesta una inferioridad construida en la mujer versus hombre. Ella es quien trabaja en el ámbito privado, mientras que ellos tienen el privilegio de pertenecer a la vida pública. Además, ellas solo son aceptadas cuando cumplen con este prototipo occidental a diferencia de Studio Ghibli, productora en la que se empodera a la mujer y se la libera (Gómez, 2016). De hecho, la bruja independiente y autónoma es la antagonista en occidente y la protagonista en oriente.

El mundo Disney opta por "la construcción de las mujeres y las niñas como otras subordinadas y deficientes que no pueden participar como pares en la vida social" (Fraser, 2011, p. 299) quienes de acuerdo con el posicionamiento clásico de Bordieu (2000) "sólo pueden aparecer en el orden social como un símbolo cuyo sentido se construye al margen de ellas, cuya función es contribuir a la perpetuación o aumento del capital simbólico poseído por los hombres" (p. 37). En contraposición, Studio Ghibli visibiliza al personaje femenino y le dota de "potencial crucial para el cambio, el crecimiento y el empoderamiento compasivo" (Napier, 2000, p.124); también las define como "notablemente independientes y activas, confrontando valientemente la variedad de obstáculos que se les presentan de una manera que podría ser descrita estereotipadamente como masculina" (Napier, 2000, p. 124). De hecho, así lo comparten Aguado y Martínez (2016).

Desde las inocentes y traviesas niñas hasta las sabias y solemnes ancianas, la palabra que aglutina a los personajes femeninos de Miyazaki es el empoderamiento. Mujeres que controlan sus vidas, toman decisiones y participan de forma activa en la consecución de sus deseos. Mujeres fuertes, independientes, inteligentes, habilidosas, pero también empáticas y cuidadoras, domi- 
nan la narrativa de estas ficciones, repartiéndoselo entre protagonistas, secundarias y extras. Una hiperrepresentación de este género que ocupa el centro de la trama, reservando el espacio del apoyo y la complementariedad a sus compañeros varones. (pp. 209-210)

La bruja es una villana clave en la literatura infantil y juvenil que desde tiempos pretéritos encarna la figura de la mujer empoderada, autónoma, independiente y que contradice las explicaciones cristianas sobre la existencia; por ello se la define de una manera connotativamente negativa en occidente. Asimismo, Disney refleja esta construcción social en sus propias creaciones con ejemplos como la bruja de Blancanieves y los siete enanitos(Disney, 1937) o MadamMim de Merlín, el encantador (Disney, 1963). Únicamente, se advierte la presencia de una mujer aprendiz de bruja a quien se la considera figura protagonista y bondadosa, ya que en su largometraje es la encargada de cuidar a tres hermanos huérfanos tras el paso de la II Guerra Mundial. Esta es Eglantine Price de La bruja novata (Walsh, 1971), una señora madura que estudia un curso de brujería por correspondencia para alcanzar la fórmula del hechizo de la locomoción sustitutiva como medio para vencer al ejército alemán en la batalla.

Este último ejemplo se relaciona en gran medida con la visión que crea, recrea y transmite Studio Ghibli sobre las brujas. Concibe a la mujer como un ser capaz de cambiar la realidad, reconociéndola y preservándola; posicionándose así en una teoría feminista (Pérez-Guerrero, 2013). Dentro de esta compañía se cuenta con Nicky una joven estudiante de 13 años que comienza su formación fuera de casa en Nicky la aprendiza de bruja(Miyazaki y Hara, 1989) o también la bruja del páramo quien tras despojarse de su banalidad se convierte en un personaje positivo y clave para la trama de El castiIlo ambulante(Miyazaki, Suzuki e Ishii, 2004). Con todo, resulta significativo citar a Bethelheim (2006) debido a su importancia histórica como antecedente a los estudios de género sobre la literatura infantil y popular; tomándolo también como referencia para el estudio de largometrajes en esta investigación.

\section{Figura 1}

La bruja como condición arquetípica de la mujer villana en Disney. La bruja de Blancanieves [Figura]. En "Blancanieves y los siete enanitos" (Disney, 1937)

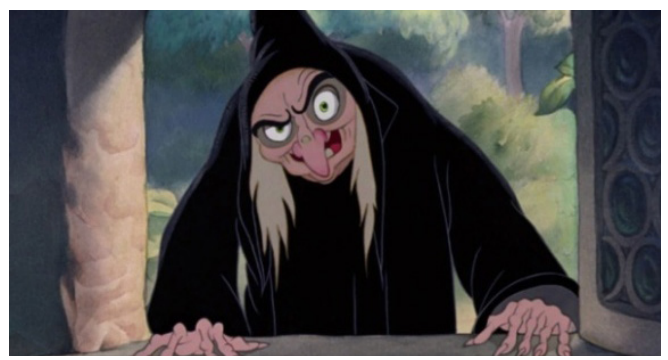

\section{Figura 2}

La bruja como representación de la autonomía y del protagonismo en los filmes de Studio Ghibli. Nicky buscando un lugar para iniciar su formación como bruja [Figura]. En "Nicky, la aprendiza de bruja" (Miyazaki y Hara, 1989)

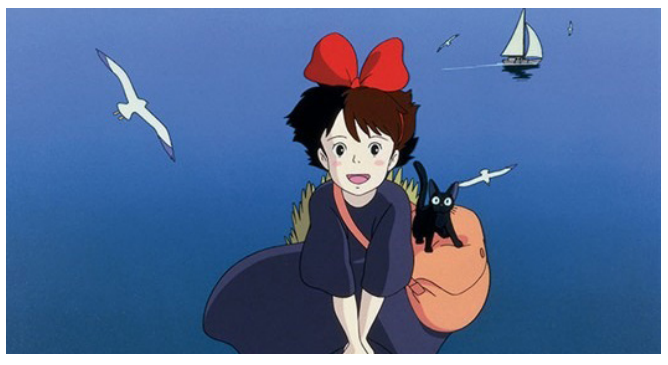


Como consecuencia, ya que estas mujeres se presentan empoderadas e independientes de los hombres, no necesitan experimentar un amor romántico de cariz heterosexual con un varón que las salve; ellas mismas disponen de medios para liberarse sin ayuda de un igual. Por ello, las relaciones entre estas y sus opuestos en sexo se limita a la amistad.

En los largometrajes de Disney se defiende un amor romántico (Marín y Solís, 2017) como sentimiento ideal a alcanzar entre dos personas, entendido como una necesidad para la mujer y un privilegio para el varón. Apreciándose un total de $42 / 60$ películas que lo defiende. En contraposición, en Studio Ghibli, las narrativas carecen de dicho componente ya que se defiende con una importancia mayor la amistad, posibilitándola sin componente sexual entre sexos opuestos.

En Disney, la mayoría de las historias filmadas versan sobre la existencia de un amor de corte romántico entre la pareja de protagonistas y las dificultades que experimentan hasta que finalmente lo consuman. De hecho, la productora occidental impone una tendencia que obliga a las personas a buscar y encontrar a su opuesta en sexo, defendiendo un posicionamiento filosófico clásico respecto al sentimiento. Estos mensajes dañan y niegan cualquier tipo de diversidad y/o de rotura respecto a lo que se entiende por normativo. De hecho, a lo largo de los 60 largometrajes analizados se sigue una misma estructura. Las mujeres se presentan indefensas y sumisas; necesitan un hombre que las salven - mostrando únicamente relaciones entre personas blancas y de clase social elevada - mientras que ellos son quienes les aseguran la tranquilidad e incluso las liberan de un destino trágico. Los casos más significativos se presentan con Blancanieves de Blancanieves y los siete enanitos(Disney, 1937) y Aurora de La bella durmiente(Disney, 1959) ya que en ambos ejemplos regresan a la vida tras el beso de sus amados, personas a quienes no ven más de una vez en sus vidas y con quienes solo comparten una comunicación a través de la interpretación de melodías y canciones.

A medida que la colección avanza en el tiempo se manifiesta un cambio en la concepción del príncipe y son ellas quienes los liberan a ellos, aunque ello les suponga una pérdida de autonomía y libertad. Rapunzel de Enredados(Conli, 2010) accede a vivir encerrada con su secuestradora si esta protege a su amado; Tiana de Tiana y el sapo(del Vecho y Lasseter, 2009) renuncia a abrir un restaurante por ayudar a que su príncipe no fallezca. Con esta tendencia, Disney las dota de identidad para posteriormente arrebatársela con la presencia de un varón, quien desde su primer encuentro las condiciona.

No obstante, esta directriz se rompe con el último largometraje analizado siendo la protagonista del filme Vaiana(Shurer, 2016) quien en sus aventuras es acompañada por un semi-dios en masculino quien únicamente se limita a desarrollar con ella una relación de amistad. Con este ejemplo, se encuentra un punto de inflexión y relación más directa con los vínculos afectivos establecidos entre sexos opuestos en Studio Ghibli. En la compañía oriental ambas personas se complementan y ayudan mutuamente sin esperar un cambio en la materialización del sentimiento. De hecho, la reciprocidad es mutua tal y como se manifiesta entre Chihiro y Haku en El viaje de Chihiro (Suzuki, 2001).

\section{Figura 3}

El amor romántico Disney materializado con la figura del beso entre personas de sexo opuesto. Ejemplo amoroso de Aurora y el príncipe Felipe [Figura]. En "La bella durmiente"(Disney, 1959)

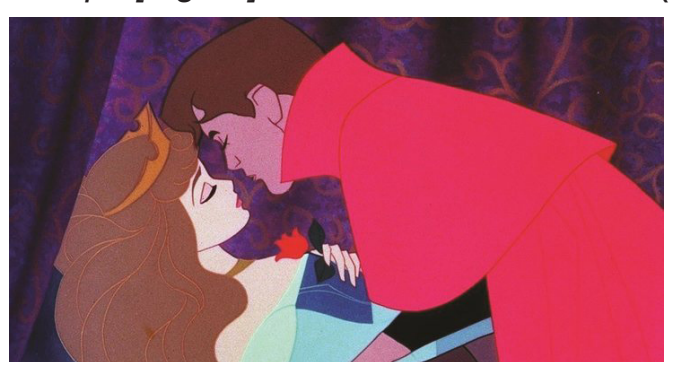




\section{Figura 4}

El valor de la amistad entre sexos opuestos en Studio Ghibli. Ejemplificación del sentimiento entre Chihiro y Haku [Figura]. En "El viaje de Chihiro" (Suzuki, 2001)

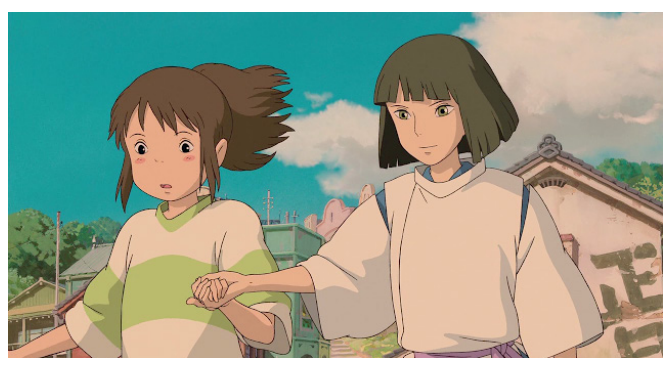

Ambas productoras presentan cierto fanatismo religioso en su ideología. Por un lado, Disney impone un dogma cristiano en aras de extenderlo a nivel mundial (Laderman, 2016) con un conjunto de 29/60 filmes en los que aparece. Por otro lado, Studio Ghibli manifiesta en todos sus largometrajes elementos del sintoísmo para preservar los derechos de la naturaleza. Diferenciándose únicamente en la forma de presentación. La primera achaca la posibilidad de existencia de otros dogmas, mientras que la segunda plantea el sinto como una opción entre una pluralidad. De hecho, mientras que el cristianismo tiende a imponer la figura de un dios - a quien se le atribuye el sexo de hombre - que conlleva machismo en la propia esencia religiosa; el sintoísmo se basa en tradiciones orientales y que combinan pensamientos de diferentes culturas según los que la deidad se ubica en elementos con vida e inertes en la propia naturaleza, razón por la que se entiende la veneración y cuidado del propio medio; destacándose la materialización de estas en unas figuras humanas y con un sexo determinado. En el sinto quienes ostentan el poder religioso son espíritus y/o almas que carecen de atributos de la humanidad.

En Disney la carga de religión se relaciona con el cristianismo ya que es el dogma con el que pretende adoctrinar a la población. Por ello, aparecen iglesias, se hace referencia a pasajes bíblicos e incluso se desarrollan rituales propios de la misma como el rezo o el matrimonio como sacramento. Se destaca el ejemplo de El jorobado de Notre Dame(Hahn, 1996) ya que la mayor parte de la trama se ubica en la catedral de Nuestra Señora de París como espacio principal. De hecho, niega a la alteridad o la ridiculiza en el caso de presentarla. Por ejemplo, el semi-dios Maui como deidad de la cultura de indonesia es tildado de villano no apto para la profesión en Vaiana(Shurer, 2016). Asimismo, en el caso de Aladdin(Clements y Musker, 1992), a pesar de contextualizar la historia en un ambiente árabe no se alude a la religión de dicho lugar. Por ello, se comparte la siguiente reflexión: ¿qué mayor opresión se puede ejercer sobre un colectivo sino la negación del mismo?

En contraposición, en Studio Ghibli, este fanatismo religioso se presenta en todas sus historias. Estas se contextualizan en oriente (en su mayoría) y se alude únicamente a las creencias, culturas, hábitos, etc., tradicionales de dicho dogma. Se alude al sintoísmo como religión. En largometrajes como La princesa Mononoke (Suzuki, 1997) se referencia desde las primeras escenas en la que se alude al binomio ético de la bondad-maldad, siendo los demonios malignos quienes se apoderan de las deidades relacionadas con la propia naturaleza, oscureciéndola y destruyéndola.

\section{Figura 5}

La imposición cristiana a través de los largometrajes Disney. Archidiácono de Nuestra Señora de París [Figura]. En "El jorobado de Notre Dame" (Hahn, 1996)

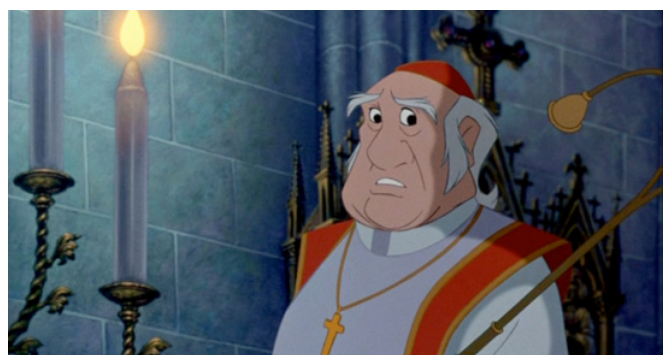




\section{Figura 6}

El sintoísmo como religión naturalista en Studio Ghibli. Materialización de un espíritu de la naturaleza [Figura]. En "La princesa Mononoke" (Suzuki, 1997)

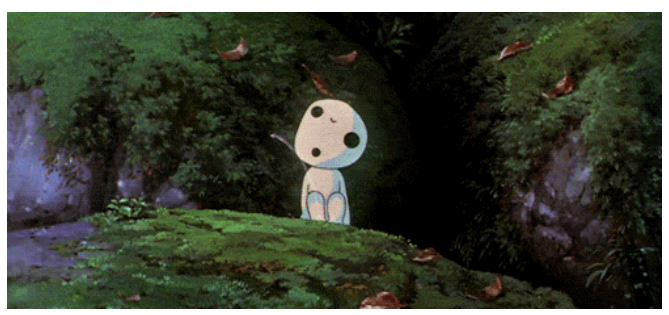

Finalmente, se valora como positivo el impulso que ambas empresas ofrecen a la necesidad de preservación del medio ambiente y de los derechos del reino animal con un total de 24/60 películas donde se manifiesta en Disney. En Studio Ghibli aparece reflejada como la variable más característica por el fondo de la religión que persigue y presenta en sus obras. "Las películas de Miyazaki destacan porque el ecologismo y el pacifismo están siempre en el centro de la trama, bien sea desde escenarios idealizados [‥], desde el conflicto [‥] o apocalípticos" (Aguado y Martínez, 2016, p. 208). Mostrando así la necesidad de abogar por una conexión con el medio natural desde una perspectiva de corte espiritual. No simplemente plateándose como una crítica sutil que en ocasiones introduce Disney en sus obras. En Studio Ghibli prima una espiritualidad basada en el budismo y sintoísmo; también en el politeísmo. "Más que proclamar la divinidad de un líder, de un pueblo o de un territorio, proclama la divinidad de la naturaleza en su conjunto" (Hernández, 2013, p. 28), ya que en esta productora se transmite una idea de preservación de medio ambiente por la condición de divinidad que encierra dicho lugar en el mundo. De hecho, en todas sus historias la conexión entre la humanidad y el entorno natural es una evidencia. Un ejemplo a destacar es La princesa Mononoke(Suzuki, 1997). Asimismo, en Disney hay una tendencia a convertir a las personas de los filmes en figuras villanas cuando desarrollan actividades de caza, pesca, etc., o cualquier otra que atente contra la vida del reino animal, y en ocasiones también, contra el vegetal. Un ejemplo significativo se encuentra en Bambi (Disney, 1942) cuando la propia humanidad asesina a la madre del cervatillo condicionándole a este a la orfandad. Algunas pinceladas sobre Disney y medio ambiente también son compartidas por Romañá (1996).

\section{Figura 7}

Visión de quienes arremeten contra la naturaleza como figuras villanas en Disney. Asesinato de la madre de Bambi por parte de la ciudadanía [Figura]. En "Bambi" (Disney, 1942)

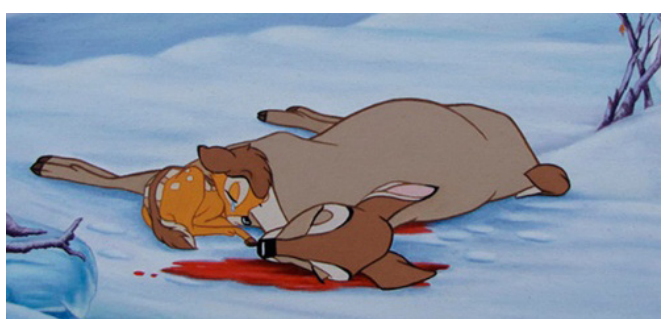

\section{Figura 8}

Conexión entre humanidad y naturaleza fomentando la preservación del medio ambiente en Studio Ghibli. Mononoke y el lobo del bosque [Figura]. En "La princesa Mononoke" (Suzuki, 1997)

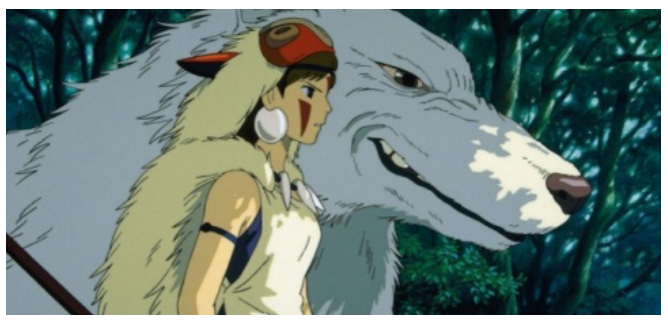


Una vez establecida la comparativa entre ambas productoras en el apartado de resultados y discusión es posible compartir las siguientes conclusiones:

Disney se etiqueta como machista mientras que Studio Ghibli apuesta por principios feministas. Por ello, si se recurre a productos audiovisuales de la primera compañía es preciso diseñar actividades que sirvan como contra-discurso para los mensajes difundidos por la misma. En el segundo caso, resultan un material idóneo para el desarrollo de la coeducación en las aulas.

El amor romántico Disney de corte heterosexual se cambia por una relación de amistad en la productora oriental. En Educación Infantil tiende a defenderse mucho más el sentimiento de la amistad ya que es aquel que aflora en dichas aulas. Por ello, se recomienda recurrir a los filmes de Studio Ghibli para asegurarlo y mostrarlo como ejemplo. Nuevamente, en el caso de Disney se precisan actividades complementarias al visionado de filmes que ayuden a quienes estudian a no etiquetar el sentimiento de amor heteronormativo como la única manifestación válida y dar cabida a cualquier tipo de diversidad.

La compañía occidental defiende un dogma cristiano, criticando y achacando otras espiritualidades; al tiempo que Studio Ghibli apuesta por un sintoísmo. En ambos casos hay una tendencia fanática ya que únicamente se promueve y defiende una creencia religiosa. Por ello, a partir de estos ejemplos es necesario diseñar talleres de ampliación para compartir con el grupo-clase una pluralidad de opciones y de creencias religiosas que sirvan para que cada menor se identifique y para que tolere cualquier otra alterosa.

La preocupación por el medio ambiente es una constante en ambas productoras. En consecuencia, se propone recurrir a las escenas más significativas de sus filmes como actividades de introducción y/o motivación cuando se pretende concienciar a un grupo de alumnado sobre la importancia de cuidar y preservar el medio ambiente.

Con todo, los productos audiovisuales tienen un trasfondo y entramado de mensajes, ideologías, mentalidades, etc., que quienes tienen el poder quieren transmitir entre el colectivo infantil para adoctrinar y generar una uniformidad social. Por ello, se anima a que las plantillas docentes que utilizan estos recursos artísticos en sus aulas, los analicen de una manera crítica previamente a su utilización. De esta manera, tras conocer el trasfondo ideológico y político de las mismas tienen la posibilidad de diseñar propuestas complementarias como las presentadas y sugeridas en este apartado.

\section{Referencias}

Acaso, M.(2006). Esto no son las torres gemelas. Cómo aprender a leer la televisión y otras imágenes. Los Libros de la Catarata.

Aguado, D. y Martínez, P.(2016). El modelo femenino en Studio Ghibli: un análisis del papel de las mujeres en Hayao Miyazaki en Gómez (Ed.), Japón y Occidente. El patrimonio cultural como punto de encuentro(pp. 203-212). Aconcagua Libros.

Alonso-Sanz, M.A.(2013). A favor de la Investigación Plural en Educación Artística. Integrando diferentes Enfoques Metodológicos.Arte, Individuo y Sociedad, 25, 111-119.https://doi.org/10.5209/rev_ ARIS.2013.v25.n1.41167.

Anónimo. (2016). En 30 años de Studio Ghibli: Sus 22 películas. https://n9.cl/g3v8.

Anónimo. (2020). En Colecciones clásicas de Disney. https://n9.cl/c8l0.

Asebey, A.M.D.R.(2011). Disney y la aculturización de la niñez latinoamericana.Revista Psicología, 13, 241-251.https://n9.cl/rnm8.

Bethelheim, B. (2006). Psicoanálisis de los cuentos de hadas. Crítica. 
Bordieu, P.(2000). La dominación masculina. Anagrama.

Del Arco, I.(2007).Simbolismo y funcionalidad arquitectónica en dos mitos: Blancanieves y Walt Disney. Culturas Populares. Revista Electrónica, 5, 1-19.https://n9.cl/dw8em.

Farías, M. yAraya-Seguel, C.(2014). Alfabetización visual crítica y educación en lengua materna: estrategias metacognitivas en la comprensión lectora de textos multimodales.Colombian Applied Linguistics Journal, 16, 93-104.https://n9.cl/g0t7.

Fraser, N.(2011). Dilemas de la Justicia en el Siglo XXI. Género y Globalización. Universidad de les Illes Balears.

Giroux, H.(1995).Animating youth: The Disneyfication of children's culture.SocialistReview, 24, 65-79. https://n9.cl/qxlo.

Gómez, A.(2016). Japón y Occidente. El patrimonio cultural como punto de encuentro. Aconcagua Libros.

Laderman, G.(2000). The Disney Way of Death. Journal of the American Academy of Religion, 68, 27-46. https://n9.cl/zqlp.

Lluch, G.(2007). De los narradores de cuentos folclóricos a Walt Disney. Un camino hacia la homogeneización en Lluch (coord.). Invención de una tradición literaria: de la narrativa oral a la literatura para niños (pp. 17-52).Norma.

Maeda, C. M.(2011). Entre princesas y brujas: análisis de la representación de las protagonistas y las antagonistas presentes en las películas de Walt Disney. En Mateaos (coord.), Actas del III Congreso Internacional Latina de Comunicación Social (pp. 97). Universidad de la Laguna.

Marín, V. y Solís, C.(2017). Los valores transmitidos por las mujercitas de las películas Disney. Revista CS, 23, 37-55.https://n9.cl/f2rm.

Martínez, J.D.(2015). La filosofía del viento: un análisis del lenguaje en el cine de Hayao Miyazaki. Hojalata, 6, 7-13.https://n9.cl/7bnmv.

Mollet, T.(2013). With a smile and a song...Walt Disney and the Birth of the American Fairy Tale.Marvels\& Tales, 27, 109-124.https://n9.cl/qi7t.

Monleón, V.(2018). El malo de la película. Estudio de las principales figuras malvadas en la colección cinematográfica clásicos Disney (1937-2016). EARI Educación ArtísticaRevista de Investigación, 9, 131-148.https://doi.org/10.7203/eari.9.12212.

Napier, S.(2000). Anime from Akira to Princess Mononoke. Experiencing Contemporary Japanese Animation. Palgrave.

Papalini, V.(2006). Anime. Mundos tecnológicos, animación japonesa e imaginario social. La Crujía Ediciones.

Pérez-Guerrero, A.M. (2013). La aportación de los personajes femeninos al universo de Hayao Miyazaki. Con A de animación, 3, 108-121.https://doi.org/10.4995/caa.2013.1428.

Ramos, C.A.(2015). Los paradigmas de la investigación científica.Av. psicol., 23, 9-17. https://n9.cl/e7hy.

Robles, M.(2013). Antología del Studio Ghibli. De los Yamada a Kokuriko.Colección Manga Books.

Romañá, M.T. (1996). Éticas ambientales: variantes de la formación ambiental. Teoría de la educación, 8, 141-151.https://n9.cl/tfp1. 
Referencias fílmicas

Clements, R. y Musker, J. (productores) y Clements, R. y Musker, J. (directores). (1992). Aladdin [Cinta cinematográfica]. EstadosUnidos: Walt Disney Pictures y Walt Disney Feature Animation.

Conli, R. (productor) y Greno, N. y Howard, B. (directores). (2010). Enredados [Cinta cinematográfica]. Estados Unidos: Walt Disney AnimationStudios.

Del Vecho, P. y Lasseter, J. (productores) y Clements, R. y Musker, J. (directores). (2009). Tiana y el sapo [Cinta cinematográfica]. EstadosUnidos: Walt Disney Pictures.

Disney, W. (productor) y Algar, J., Armstrong, S., Hand, D., Heid, H., Roberts, B., Stterfield, P. y Wright, N. (directores). (1942). Bambi [Cinta cinematográfica]. Estados Unidos: Walt Disney Productions.

Disney, W. (productor) y Clark, L., Geronimi, C., Larson, E. y Reitherman, W. (directores). (1959). La bella durmiente [Cinta cinematográfica]. EstadosUnidos: Walt Disney Animation Studios.

Disney, W. (productor) y Cottrell, W., Hand, D., Morey, L., Pearce, P. y Sharpsteen, B. (directores).(1937). Blancanieves y los siete enanitos [Cinta cinematográfica]. Estados Unidos: Walt Disney Pictures.

Disney, W. (productor) y Reitherman, W. (director). (1963). Merlín, el encantador [Cinta cinematográfica]. Estados Unidos: Walt Disney Pictures.

Hahn, D. (productor) y Trousdale, G. y Wise, K. (directores). (1996). El Jorobado de Notre Dame [Cinta cinematográfica]. EstadosUnidos: Walt Disney Pictures y Walt Disney Feature Animation.

Miyazaki, H. y Hara, T. (productores) y Miyazaki, H. (director). (1989). Nicky la aprendiza de bruja [Cinta cinematográfica]. Japón: Studio Ghibli.

Miyazaki, H., Suzuki, T. e Ishii, T. (productores) y Miyazaki, H. (director). (2004). El castillo ambulante [Cinta cinematográfica]. Japón: Studio Ghibli, TokumaShoten, NTV, Nibariki, Dentsu, Walt Disney Studios Home Entertainment, Mitsubishi y Toho.

Shurer, O. (productor) y Clements, R. y Musker, J. (productor). (2016). Vaiana [Cinta cinematográfica]. EstadosUnidos: Walt Disney Pictures y Walt Disney Animation Studios.

Suzuki, T. (productor) y Miyazaki, H. (director). (1997). La princesa Mononoke[Cinta cinematográfica]. Japón: Studio Ghibli.

Suzuki, T. (productor) y Miyazaki, H. (director). (2001). El viaje de Chihiro [Cinta cinematográfica]. Japón: Studio Ghibli.

Walsh, B. (productor) y Stevenson, R. (director). (1971). La bruja novata [Cinta cinematográfica]. EstadosUnidos: The Walt Disney Company. 